\section{Notices of Meetings}

An international conference on "East-West Collaboration in Health Issues: Challenges for the Year 2000" will be held at the Royal College of Physicians in London on 2-3 October 1989. The programme covers epidemiology and health services research (as main forums), clinical trials, biomedical research, biomedical engineering and post marketing drug surveillance.

Further details from East-West Collaboration in Healthcare Issues Conference Office, Concorde Services Ltd, 10 Wendell Road, London W12 9RT, phone 01-743 3106.

A regional European meeting of the International Epidemiological Association will take place in Granada, Spain, on February 14-16, 1990. The meeting is intended to focus the attention of European epidemiologists on the evaluation of the "Health for all" strategy and on current problems in its implementation. Official languages will be English and Spanish. For further information contact Jose $\mathbf{M}$ Martin-Moreno, Regional European Meeting IEA1990, Escuela Andaluza de Salud Publica, Apdo Correos 668, 18080 Granada, Spain.

The XII World Congress on Occupational Safety and Health will take place in Hamburg on 6-11 May 1990. Further details from German Organising Committee, Postfach 2052, D-5205 Sankt Augustin 2, Federal Republic of Germany, phone 02241-231358.

SYSTED 90: The Third International Conference on Systems in Health-Social Services for the Elderly and the Disabled will be held on April 17-21 1990 in Bologna, Italy. The objectives are to address the problems of planning, organising and managing health and social services for the elderly and the disabled. Abstracts by December 15. Further details from Professor Pier Paolo Puliafito, Università di Genova, Viale Causa 13, 16145 Genova, Italy; Fax no 39-10-310086.

\section{Announcements}

Domestos Health Education Awards. Domestos are offering cash prizes totalling $£ 4500$ to health professionals for community health education projects, with a special category relating to AIDS. Application forms from The Domestos Advisory Service, 50 Upper Brook St, London W1Y 1PG; phone 01-491 4568.

Technical Assessment Systems, Inc (TAS) is working with the US National Cancer Institute (NCI) on a three year project to collect international food consumption survey data and to enter summary data into a IBM-PC compatible data management and analysis system called FOODBASE. FOODBASE will be a powerful but straightforward tool for nutritionists, epidemiologists, medical researchers, and other health professionals to use in assessing the intake of foods and food constituents by peoples throughout the world. NCI will use FOODBASE to investigate relationships between diet and cancer incidence. However, the system will be equally useful for investigation of other diet-disease relationships and for endeavours such as chemical exposure assessment, nutrition education, nutritional anthropology, and food industry research. We hope that the many people around the world with expertise in food consumption or food disappearance will provide assistance and thus minimise the difficulty of this project. Our ultimate goal is to make the information we gather and the tools that we develop available to as many countries and institutions as possible. FOODBASE data contributors will be reimbursed for expenses and will receive a copy of the database. For further information, or to contribute data, please contact Dr Barbara Petersen, Judi Douglass, or Dr Kathryn Fleming, TAS, Inc, 1000 Potomac St, NW, Washington, DC 20007 USA (Telephone: 202-337-2625). 